\title{
Comparative Evaluation of Root Resorption in Correction of Class II Malocclusion
}

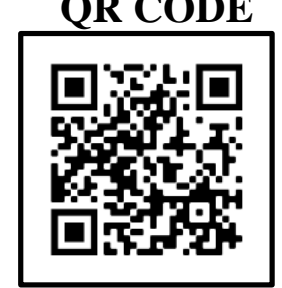

\section{PRIYANKA', YAGYESHWAR MALHOTRA² (Corresponding Author)}

INTRODUCTION: External apical root resorption is a common iatrogenic side effect of orthodontic treatment and has been reported particularly in anterior teeth. The etiology of resorption is multifactorial, complex and individual susceptibility to resorption depends on various factors.

MATERIALS AND METHOD: The degree of root resorption during orthodontic treatment was evaluated on the post-treatment RVGs of the maxillary and mandibular central and lateral incisors of 28 skeletal Class II patients with mandible retrusion treated with non-extraction treatment protocol using elastics and PowerScope.

RESULTS: There was no statistically significant difference in root resorption between the groups for the overall score and comparison of root resorption in individual teeth between two groups showed significantly more resorption in PowerScope group in mandibular lateral incisors.

CONCLUSION: Both elastic and PowerScope groups showed mostly mild to moderate root resorption which is clinically acceptable and lower lateral incisors showed statistically more root resorption in PowerScope group.

KEYWORDS: Resorption, PowerScope, Malocclusion

\section{INTRODUCTION}

Class II malocclusion with mandibular retrusion is one of the major reasons for patients seeking orthodontic treatment. ${ }^{1,2}$ Different treatment modalities are available for its treatment depending upon the age, severity of antero-posterior discrepancy, clinical evaluation, cephalometric hard and soft tissue analysis and patient's compliance etc. ${ }^{3}$ One of the most widely used techniques to correct Class II malocclusion in growing patients is functional jaw orthopedics through mandibular advancement to stimulate mandibular growth by forward positioning of the mandible..$^{4-6}$

With the pioneer work of Calvin S Case and Henry A Baker, use of intermaxillary elastics has been a standard procedure for the correction of class II malocclusion. ${ }^{7,8}$ Intermaxillary elastics are effective in treating anteroposterior discrepancy of dentition but undesirable side effects have been reported due to vertical force vector with intermaxillary elastics. ${ }^{7-9}$ Removable functional appliances have now been replaced by fixed functional appliances to overcome two major limitations of removable appliances- need for patient compliance and longer treatment duration. PowerScope (American orthodontics, USA) a semi-rigid one piece, one size- fit all hybrid fixed appliance was introduced by Andy Hayes. ${ }^{10}$ It is simple in design, hygienic, and requires less inventory, delivering consistent forces than the other fixed functional appliances. ${ }^{11-13}$

External apical root resorption is a common iatrogenic side effect of orthodontic treatment and has been reported particularly in anterior teeth. There is more than $90 \%$ occurrence of external apical root resorption reported by histological studies and radiographic evaluation studies reported between $48 \%$ and $66 \%$ occurrence. ${ }^{14-21}$ The etiology of resorption is multifactorial and complex and individual susceptibility to resorption depends on various factors such as tooth root morphology, type of tooth movement, genetics, chronological age, treatment duration and magnitude of applied force etc. ${ }^{22-30}$

The purpose of this study was to compare the apical root resorption in class II patients with mandible retrusion treated by use of elastics and PowerScope fixed functional appliance as there is no study published in which there is comparison of root resorption between PowerScope and intermaxillary elastics in the treatment of Class II malocclusion.

\section{MATERIALS AND METHOD}

The study was conducted in the department of

(c) Priyanka et al. This is an open access article distributed under the terms of the Creative Commons Attribution License CC-BY-NC 4.0, which permits unrestricted use, distribution and reproduction in any medium, provided the use is not commercial and the original author(s) and source are cited. 
Orthodontics and Dentofacial Orthopedics and included 28 skeletal Class II patients with mandible retrusion treated with non-extraction treatment protocol in the age group of 12-16 years. The subjects were randomly allocated into two groups.

The groups were as follows: Elastic group- 14 patients treated with class II elastics and PowerScope group- 14 patients treated with PowerScope appliance.

\section{INCLUSION CRITERIA}

1. Patients with skeletal Class II malocclusion, requiring skeletal mandibular sagittal correction

2. Molar relation with a minimum of half the cusp width of Class II molar relationship

3. Treatment completed without any permanent tooth extraction (excluding third molars)

4. Moderately increased overjet

5. Mild to moderately increased overbite

6. Reduced or normal lower facial height

7. Lower dental arch crowding $<3 \mathrm{~mm}$

8. Maxillary midline coincident with the facial midline 9. Positive clinical Visual treatment objective (VTO)

10. No history of any systemic medical illness

11. Good quality pretreatment and post-treatment periapical and pretreatment cephalometric radiographs

\section{EXCLUSION CRITERIA}

1. Incompletely formed roots or any sign of root resorption

2. Pretreatment signs and symptoms of temporomandibular joint dysfunction

3. History of trauma

4. Endodontically treated incisors

5. Missing incisors or peg lateral incisors

In both groups patients were treated with 0.022 " MBT pre-adjusted edgewise appliance following a usual wire sequence. Maxillary and mandibular arch wires (o.019" X 0.025 " SS) were left in place for 6 weeks for complete leveling and alignment in the elastics group, class II elastics of 3/16-inch diameter and 4.5-ounce force on both sides were used for 15-18 hours/day. Elastics extended from the canine hook to the mandibular first molar (figure 1). PowerScope was installed by securing wire attaching nuts to the maxillary and mandibular arch wires, mesial to the first molar in the maxillary arch and distal to the canine in the mandibular arch (figure 2). Activation of the appliance was done by the addition of shims on the pushing rod till it covered the activation black dot on the appliance. A labial root

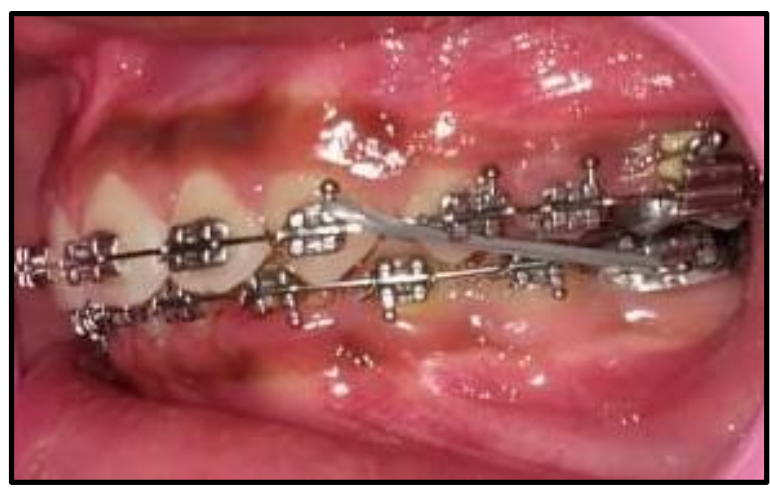

Figure 1. Intraoral photograph showing class II malocclusion treatment with elastics

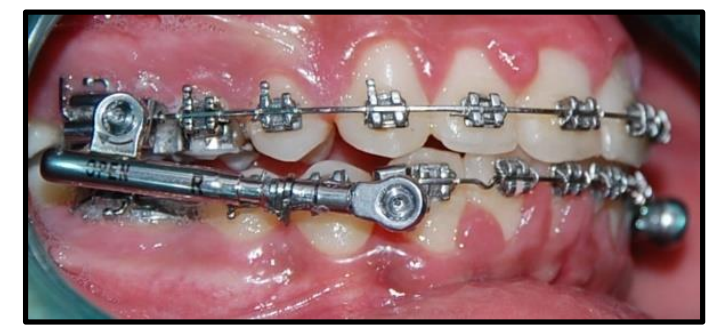

Figure 2. Intraoral photograph showing class II malocclusion treatment with PowerScope

torque was placed in the .019 X .025 mandibular arch wire in anterior region so that minimum proclination of the mandibular incisors takes place and wire was cinched distal to the molar tube. Pre and post treatment RVG of maxillary and mandibular incisors were obtained using Acteon Satelec dental RVG unit using sensor positioner (figure 3). The initial and final periapical radiographs were scanned and images were analyzed with Photoshop software (version 7.0; Adobe Systems, San Jose, California) at 300\% enlargement, without image quality loss.

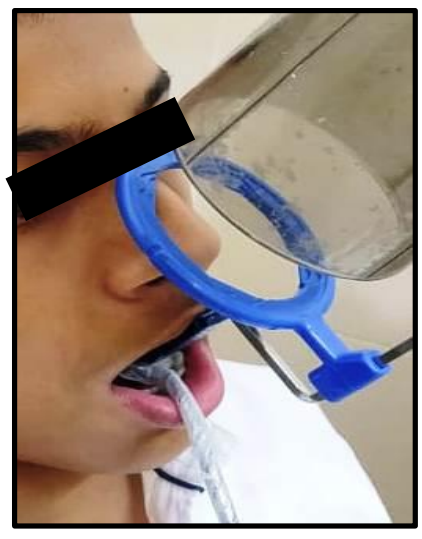

Figure 3. Taking RVG of incisors using sensor positioner 
The degree of root resorption during orthodontic treatment was evaluated on the post-treatment RVGs of the maxillary and mandibular central and lateral incisors using the score system of Malmgren et al. (figure 4). Signs of apical root resorption were recorded according to 5 scores defined from o to 4 with o, no root resorption; 1, mild resorption, with the root of normal length and only an irregular contour; 2, moderate resorption, with small areas of root loss and the apex having an almost straight contour; 3 , severe resorption, with loss of almost one third of root length; and 4, extreme resorption, with loss of more than one third of the root length.

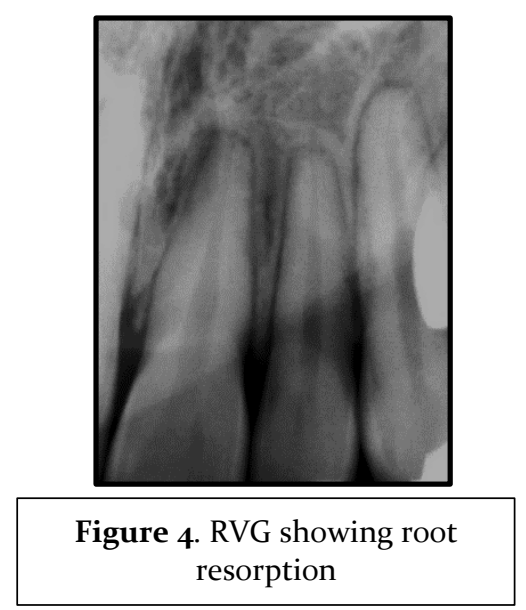

The pre-treatment cephalometric radiographs were hand traced on celluloacetate paper, landmarks were identified and a customized cephalometric analysis was done to make a baseline data to compare homogeneity between two groups.

Statistical analysis: A master file was created by entering data into a Microsoft Excel spreadsheet and data were analyzed using SPSS (version 21.0 SPSS, Chicago, Ill). The data were subjected to descriptive analysis for proportion, mean, and standard deviation. Intergroup root resorption was compared with MannWhitney U tests, as an overall score for the groups and for each tooth. Descriptive statistics were used to show the tooth distribution among the scores of root resorption according to the method of Malmgren et al. ${ }^{31}$ All statistical tests were performed at the .05 significance level.

\section{RESULTS}

The statistical comparison of the mean pre-treatment age, gender distributions (table 1) and baseline data (table 2) showing cephalometric variables did not reveal any significant difference for the two groups except for treatment time which is more for elastic group.

There was no statistically significant difference in root resorption between the groups for the overall score (table 3) and comparison of root resorption in individual teeth between two groups showed significantly more resorption in PowerScope group in mandibular lateral incisors.

The distributions of teeth in different groups according to 5 scores of root resorption are shown in table 4 .

\section{DISCUSSION}

External apical root resorption is a common sequel of orthodontic treatment that is associated with many factors. A prospective randomized clinical trial is widely accepted as excellent investigation method avoiding the limitations of design, methodology, treatment characteristics and variables related to patients but there are substantial ethical issues to consider..$^{32}$ Therefore, in this study, patients with Class II Division 1 malocclusion, with mandibular retrusion treated with Class II elastics and PowerScope fixed functional appliance were consecutively selected. The use of RVG is considered one of the methods to evaluate root resorption because of less image distortion than with panoramic or lateral cephalometric radiographs, less radiation to the patient; time-saving features and more convenience for the patients. ${ }^{26,33,34}$ Cone-beam computed tomography provides better images, but because of the amount of radiation and cost, it is indicated only in special situations. ${ }^{35-37}$

Subjective method is predominantly used in qualitative root resorption evaluation studies as it does not depend on standardization of the radiograph, projection technique, requiring only similar initial root status of the groups. ${ }^{8-40}$ Groups with similar characteristics regarding initial age, overjet, overbite, sex distribution, and severity of Class II molar relationship were considered for comparison since some of these factors could contribute to root resorption. ${ }^{27,33}$

Comparison of root resorption for the overall score between two groups showed root resorption in all anterior teeth but there was no statistically significant difference. Previous studies in which elastics and PowerScope were used as treatment modalities showed statistically significant root resorption. ${ }^{28,29,39,41-45}$ 


\begin{tabular}{|c|c|c|c|c|}
\hline PARAMETER & ELASTIC GROUP & POWERSCOPE GROUP & P VALUE & SIGNIFICANCE \\
\hline $\begin{array}{c}\text { MEAN } \\
\text { CHRONOLOGICAL } \\
\text { AGE }\end{array}$ & $\begin{array}{l}14 \text { years } 8 \text { months } \pm 1 \\
\text { year } 2 \text { months }\end{array}$ & $\begin{array}{l}14 \text { years } 6 \text { months } \pm 1 \\
\text { year } 4 \text { months }\end{array}$ & .0326 & NS \\
\hline $\begin{array}{c}\text { SKELETAL AGE } \\
\text { CVMI } 3 \\
\text { CVMI } 4 \\
\text { CVMI } 5\end{array}$ & $\begin{array}{l}1 \\
5 \\
4\end{array}$ & $\begin{array}{l}2 \\
4 \\
4\end{array}$ & 0.8025 & NS \\
\hline $\begin{array}{l}\text { GENDER } \\
\text { Male } \\
\text { Female }\end{array}$ & $\begin{array}{l}6 \\
8\end{array}$ & $\begin{array}{l}7 \\
7\end{array}$ & 1 & NS \\
\hline
\end{tabular}

Table 1. Comparison of mean age and gender distribution of the participants in the two groups at the start of treatment

\begin{tabular}{|c|c|c|c|c|}
\hline VARIABLE & ELASTIC GROUP & $\begin{array}{c}\text { POWERSCOPE } \\
\text { GROUP }\end{array}$ & P VALUE & SIGNIFICANCE \\
\hline SNA & $81^{\circ} \pm 1.4^{\circ}$ & $80 \pm 2.5^{\circ}$ & 0.2843 & NS \\
\hline SNB & $76^{\circ} \pm 1.8^{\circ}$ & $75^{\circ} \pm 2.3^{\circ}$ & 0.2932 & NS \\
\hline ANB & $5^{\circ} \pm 1.6^{\circ}$ & $6^{\circ} \pm 1.9^{\circ}$ & 0.2192 & NS \\
\hline GoGn-SN & $29^{\circ} \pm 3.2^{\circ}$ & $30^{\circ} \pm 2.9^{\circ}$ & 0.4734 & NS \\
\hline IMPA & $98^{\circ} \pm 3.2^{\circ}$ & $97^{\circ} \pm 3.9^{\circ}$ & 0.5386 & NS \\
\hline Treatment time & $\begin{array}{l}2 \text { years } 1 \text { month } \pm 3 \\
\text { months }\end{array}$ & $\begin{array}{l}1 \text { year } 5 \text { months } \pm 2 \\
\text { months }\end{array}$ & 0.0001 & HS \\
\hline Overjet & $6.43 \pm 1.67 \mathrm{~mm}$ & $6.82 \pm 1.78 \mathrm{~mm}$ & 0.6195 & NS \\
\hline $\begin{array}{c}\text { Molar relation } \\
\text { Complete class II } \\
\text { Half class II }\end{array}$ & $\begin{array}{l}6 \\
8\end{array}$ & $\begin{array}{l}7 \\
7\end{array}$ & 0.142 & NS \\
\hline
\end{tabular}

Table 2. Comparison of Baseline Data in Two Groups

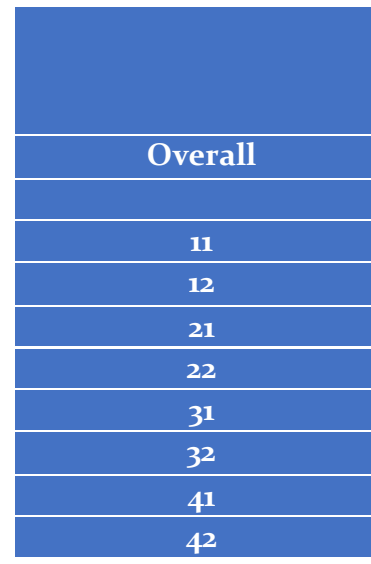

\begin{tabular}{|c|c|c|}
\hline \multicolumn{1}{|c|}{ ELASTIC GROUP } & \multicolumn{1}{c}{ POV } \\
\hline Mean & $\begin{array}{c}\text { Std. } \\
\text { Deviation }\end{array}$ & Me \\
\hline 1.1241 & .49018 & 1.37 \\
\hline 1.21 & \multicolumn{2}{|c|}{ Individual too } \\
\hline 1.50 & .802 & 1.36 \\
\hline 1.21 & .650 & 1.29 \\
\hline 1.36 & .802 & 1.43 \\
.79 & .633 & 1.5 \\
\hline 1.21 & .579 & 1.07 \\
\hline .79 & .426 & 1.71 \\
\hline 1.14 & .579 & 1.14 \\
\hline
\end{tabular}

POWERSCOPE GROUP

1.37

\begin{tabular}{|l|}
\hline 1.36 \\
\hline 1.29 \\
\hline 1.43 \\
\hline 1.50 \\
\hline 1.07 \\
\hline 1.71 \\
\hline 1.14 \\
\hline 1.57 \\
\hline
\end{tabular}

.42504

\section{Std. \\ Deviation}

.497
.726
.514
.760
.267
.825
.363
.646

Table 3. Comparison of overall and individual intergroup root resorption
P VALUE SIGNIFICANCE

\begin{tabular}{|l|l|}
\hline & \\
\hline & \\
\hline & NS \\
\hline .475 & $\mathrm{NS}$ \\
\hline .368 & $\mathrm{NS}$ \\
\hline .323 & $\mathrm{NS}$ \\
\hline .451 & $\mathrm{NS}$ \\
\hline .095 & $\mathrm{NS}$ \\
\hline $.049^{*}$ & $\mathrm{~S}$ \\
\hline .060 & $\mathrm{NS}$ \\
\hline $.043^{*}$ & $\mathrm{~S}$ \\
\hline
\end{tabular}

Comparing individual teeth in both groups, lower lateral incisors showed statistically more resorption in PowerScope group. This can be explained by the fact that, PowerScope appliance is secured to the mandibular arch wire distal to canine exerting a strong, continuous, intrusive and horizontal force vectors to mandibular anteriors. ${ }^{32,46,47}$ Surface area of mandibular incisors are less than that of other teeth making them 


\begin{tabular}{|c|c|c|c|}
\hline SCORE & $\begin{array}{c}\text { ELASTIC } \\
\text { GROUP }\end{array}$ & $\begin{array}{c}\text { POWERSCOPE } \\
\text { GROUP }\end{array}$ & TOTAL \\
\hline 0 & $12(10.7 \%)$ & $2(1.8 \%)$ & $14(6.2 \%)$ \\
\hline 1 & $\begin{array}{c}75 \\
(67.0 \%)\end{array}$ & $70(62.0 \%)$ & $145(64.7 \%)$ \\
\hline 2 & $22(19.6 \%)$ & $36(32.1 \%)$ & $58(25.4 \%)$ \\
\hline 3 & $3(2.67 \%)$ & $3(2.6 \%)$ & $6(2.6 \%)$ \\
\hline 4 & $0(0.0 \%)$ & $1(.9 \%)$ & $1(0.4 \%)$ \\
\hline Total & 112 & $112(100 \%)$ & $224(100.0 \%)$ \\
& $(100.0 \%)$ & & \\
\hline
\end{tabular}

Table 4. Distributions of teeth in different groups

more susceptible to root resorption than other teeth. ${ }^{44}$ Mandibular lateral incisors are more affected than central incisor due to the fact that force gets dissipated as it passes towards the mandibular central incisors. Elastic group showed less root resorption as the elastics can be installed and removed by the patient. The intermittent and low forces produced by Class II elastics distributed among all maxillary and mandibular teeth cannot cause unusual root resorption. ${ }^{1,49-51}$

In this study treatment time was more for elastic group than PowerScope group. This can be explained by the fact that as only elastics with medium and intermittent force were used to correct moderate to severe class II malocclusion with at least half class II molar relationship.

Therefore, elastics were used for a longer period of time to correct the antero- posterior discrepancy. The mean degree of root resorption was $\mathbf{1 . 1 2}$ for elastic and 1.37 for PowerScope group. The resorption was predominantly mild (score 1) to moderate (score 2) in both groups which is considered clinically acceptable. ${ }^{28,48,50}$

These results of present study showed root resorption in both elastics and PowerScope group groups but the values are clinically acceptable, encouraging use of fixed functional appliance PowerScope for the correction of mandibular retrusion as the use of elastics require patient compliance and longer treatment time. Future clinical studies with larger sample size and imaging techniques are required to establish the effect of removable and fixed functional appliance on root resorption of teeth when used for the correction of class II malocclusion.

\section{CONCLUSION}

Both elastic and PowerScope groups showed mostly mild to moderate root resorption which is clinically acceptable and lower lateral incisors showed statistically more root resorption in PowerScope group which may be explained by PowerScope exerting a strong, continuous, intrusive and horizontal force vectors to mandibular anterior teeth as compared to medium and intermittent forces by elastics.

\section{REFERENCES}

1. Proffit WR, Fields HW JR, Sarver DM. Contemporary orthodontics.4th ed. St Louis: Mosby-Elsevier; 2007. p. 1-15.

2. Mcnamara JA. Components of Class II malocclusion in children 8-10 years of age. Angle Orthod. 1981;51:177202.

3. Janson G, Sathler R, Fernandes TM, Branco NC, Freitas MR. Correction of Class II malocclusion with Class II elastics: a systematic review. Am J Orthod Dentofacial Orthop 2013;143:383-92.

4. Nelson C, Harkness M, Herbison P. Mandibular changes during functional appliance treatment. Am J Orthod Dentofacial Orthop. 1993;104:153-161.

5. Patel HP, Moseley HC, Noar JH. Cephalometric determinants of successful functional appliance therapy. Angle Orthod. 2002;72:410-417.

6. Cozza P, Baccetti T, Franchi L, De Toffol L, McNamara JA. Mandibular changes produced by functional appliances in Class II malocclusion: a systematic review. Am J Orthod Dentofacial Orthop. 2006;129:599.e1-12.

7. Bien SM. Analysis of the components of forces used to effect the distal movement of teeth. Am J Orthod. 1951;37:514-20.

8. Ellen EK, Schneider BJ, Sellke T. A comparative study of anchorage in bioprogressive versus standard edgewise treatment in Class II correction with intermaxillary elastic force. Am J Orthod Dentofacial Orthop. 1998;114:430-6.

9. Uzel A, Uzel I, Toroglu MS. Two different applications of Class II elastics with nonextraction segmental techniques. Angle Orthod. 2007;77:694-700. 10. Hayes A. A simple solution for unresolved Class II malocclusion. Orthodontic Products. 2014: 21; 10 11. American Orthodontics. (Online Article). Available form: $\quad$ www.americanortho.com/PowerScope.html. [Last Accessed on $25^{\text {th }}$ November, 2020] 
12. Paulose J, Antony PJ, Sureshkumar B, George SM, Mathew MM, Sebastian J. Powerscope a Class II corrector - A case report. Contemp Clin Dent 2016: 7; 221-5.

13. Keerthi VN, Kanya SD, Babu KP, Mathew A, Kumar AN. Early prevention and intervention of Class II division 1 in growing patients. J Int Soc Prevent Communit Dent 2016; 6:79-83.

14. Owman-Moll P, Kurol J, Lundgren D. The effects of a four-fold increased orthodontic force magnitude on tooth movement and root resorptions. An intraindividual study in adolescents. Eur J Orthod. 1996; 18(3):287-94.

15. Owman-Moll P, Kurol J, Lundgren D. Effects of a doubled orthodontic force magnitude on tooth movement and root resorptions. An interindividual study in adolescents. Eur J Orthod. 1996; 18(2):141-50.

16. Kurol J, Owman-Moll P. Hyalinization and root resorption during early orthodontic tooth movement in adolescents. Angle Orthod. 1998;68(2):161-65.

17. Harry MR, Sims MR. Root resorption in bicuspid intrusion. A scanning electron microscope study. Angle Orthod. 1982; 52(3):235-58.

18. Lupi JE, Handelman CS, Sadowsky C. Prevalence and severity of apical root resorption and alveolar bone loss in orthodontically treated adults. Am J Orthod Dentofacial Orthop. 1996; 109(1):28-37.

19. Levander E, Bajka R, Malmgren O. Early radiographic diagnosis of apical root resorption during orthodontic treatment: a study of maxillary incisors. Eur J Orthod. 1998;20(1):57-63.

20. Remington DN, Joondeph DR, Artun J, Riedel RA, Chapko MK. Long-term evaluation of root resorption occurring during orthodontic treatment. Am J Orthod. Dentofacial Orthop. 1989; 96(1):43-6.

21. Apajalahti S, Peltola JS. Apical root resorption after orthodontic treatment - a retrospective study. Eur J Orthod. 2007; 29(4):408-12.

22. Sameshima GT, Sinclair PM. Predicting and preventing root resorption: Part I. Diagnostic factors. Am J Orthod Dentofacial Orthop. 2001;119(5):505-10. 23. Al-Qawasmi RA, Hartsfield Jr JK,Everett ET, Flury L, Liu L, Foroud TM et al. Genetic predisposition to external apical root resorption. Am J Orthod Dentofacial Orthop. 2003; 123(3):242-52.

24. Brezniak N, Wasserstein A. Root resorption after orthodontic treatment: part 2. Literature review. Am J Orthod Dentofacial Orthop. 1993; 103:138-46.

25. Fox N. Longer Orthodontic treatment may result in greater external apical root resorption. Evid Based Dent. 2005; 6(1):21.
26. Brezniak N, Wasserstein A. Orthodontically induced inflammatory root resorption. Part II: The clinical aspects. Angle Orthod. 2002;72:180-4.

27. Brezniak N, Wasserstein A. Root resorption after orthodontic treatment: Part 1. Literature review. Am J Orthod Dentofacial Orthop. 1993;103:62-6.

28. Linge BO. Patient characteristics and treatment variables associated with apical root resorption during orthodontic treatment.Am J Orthod Dentofacial Orthop 1991;99:35-43.

29. Mirabella AD, Artun J. Prevalence and severity of apical root resorption of maxillary anterior teeth in adult orthodontic patients.Eur J Orthod 1995;17:93-9.

30. McFadden WM, Engstrom C, Engstrom H, Anholm JM. A study of the relationship between incisor intrusion and root shortening. Am J Orthod Dentofacial Orthop 1989;96:390-6.

31. Malmgren O, Goldson L, Hill C, Orwin A, Petrini L, Lundberg $M$. Root resorption after orthodontic treatment of traumatized teeth. Am J Orthod 1982;82:487-91.

32. Weltman B, Vig KW, Fields HW, Shanker S, Kaizar EE. Root resorption associated with orthodontic tooth movement: a systematic review. Am J Orthod Dentofacial Orthop 2010;137:462-76.

33. Phillips J. Apical root resorption under orthodontic therapy. Angle Orthod 1955;25:1-22.

34. Sameshima GT, Asgarifar KO. Assessment of root resorption and root shape: periapical vs panoramic films. Angle Orthod 2001; 71:185-9.

35. Ponder SN, Benavides E, Kapila S, Hatch NE. Quantification of external root resorption by low- vs high-resolution cone-beam computed tomography and periapical radiography: a volumetric and linear analysis. Am J Orthod Dentofacial Orthop. 2013;143: 7791.

36. Makedonas D, Lund H, Hansen K. Root resorption diagnosed with cone beam computed tomography after 6 months and at the end of orthodontic treatment with fixed appliances. Angle Orthod 2012;83:389-93.

37. Sherrard JF, Rossouw PE, Benson BW, Carrillo R, Buschang PH. Accuracy and reliability of tooth and root lengths measured on conebeam computed tomographs. Am J Orthod Dentofacial Orthop. 2010;137(Suppl 4):S10o-8.

38. Levander E, Malmgren O. Evaluation of the risk of root resorption during orthodontic treatment: a study of upper incisors. Eur J Orthod 1988;10:30-8.

39. Levander E, Malmgren O, Stenback K. Apical root resorption during orthodontic treatment of patients with multiple aplasia: a study of maxillary incisors. Eur 
J Orthod. 1998;20:427-34.

40. Brin I, Tulloch JF, Koroluk L, Philips C. External apical root resorption in Class II malocclusion: a retrospective review of 1- versus 2-phase treatment. Am J Orthod Dentofacial Orthop. 2003;124:151-6

41. Mavragani M, Vergari A, Selliseth N, Boe O, Wisth P. A radiographic comparison of apical root resorption after orthodontic treatment with a standard edgewise and a straight-wire edgewise technique. Eur J Orthod. 2000;22:665-74.

42. Kinzinger GSM, Savvaidis S, Gross U, Ulden N, Ludwig B, Lissone J. Effects of Class II treatment with a banded Herbst appliance on root lengths in the posterior dentition. Am J Orthod Dentofac Orthop. 2011; 139: 465-9.

43. Nasiopoulos AT, Athanasiou AE, Papadopoulos MA, Kolokithas G, Ioannidou I. Premolar root changes following treatment with the banded herbst appliance. J Orofac Orthop. 2006;67(4):261-71

44. Narendran N, Batra P, Sonar S, Singla A. Effects of class II treatment with hybrid fixed functional appliances on root length and root volume- a prospective study using CBCT. Int j sci res. 2019;8(4):28-31.
45. Janson G,Niederberger A, Garib DG, Caldas W. Root resorption in Class II malocclusion treatment with Class II elastics.Am J Orthod Dentofacial Orthop. 2016;150:585-91.

46. Chan E, Darendeliler MA. Physical properties of root cementum: part 7. Extent of root resorption under areas of compression and tension. Am J Orthod Dentofac Orthop. 2006; 129: 504-10.

47. Acar A, Canyurek U, Kocaaga M, Erverdi N. Continuous vs discontinuous force application and root resorption. Angle Orthod. 1999; 69:159-63

48. Linge BO, Linge L. Apical root resorption in upper anterior teeth. Eur J Orthod. 1983;5:173-83

49. Reitan K, Rygh P. Biomechanical principles and reactions. In: Graber $\mathrm{T}$, Vanarsdall $\mathrm{R}$, editors. Orthodontics: current principles and techniques. St Louis: Mosby; 1994. p. 96-192.

50. Tieu LD, Saltaji H, Normando D, Flores-Mir C. Radiologically determined orthodontically induced external apical root resorption in incisors after nonsurgical orthodontic treatment of class II division malocclusion: a systematic review. Prog Orthod. 2014;15:48.
Cite this article as:

Priyanka, Malhotra M. Comparative Evaluation of Root Resorption in Correction of Class
II
Malocclusion.

https://doi.org/10.26440/IHRJ/0411.02393

\section{AUTHOR AFFILIATIONS: $\left({ }^{*}\right.$ Corresponding Author)}

1. MDS, Medical officer, Health and Family Welfare Department, Himachal Pradesh (Former Reader at Himachal Dental College Sundernagar, Mandi, Himachal Pradesh-175018)

2. MDS (Orthodontics and Dentofacial Orthopedics), Senior Resident, Department of Orthodontics, Rayat Bahra Dental College \& Hospital, Mohali, Punjab 